\title{
The influence of the eutectic mixtures: salicylic acid - menthol and benzocaine - menthol on physical properties of the creams with fluconazole
}

\author{
MARIA ZUŃ ${ }^{\star}$ KATARZYNA WOJCIECHOWSKA, DOROTA DWORNICKA, EWA POLESZAK
}

Chair and Department of Applied Pharmacy, Medical University of Lublin, Poland

\begin{abstract}
Fluconazole is used in treatment of the surface mycoses of the skin. Menthol, salicylic acid and benzocaine are the components of many preparations for topical use. When mixed they form the eutectic mixtures. The purpose of our research was to prepare the antifungal creams with fluconazole containing eutectic mixture: menthol-salicylic acid or menthol-benzocaine and to compare and estimate the influence of these mixtures on physical properties of these preparations. At the beginning, the creams were subjected to physical tests such as spreadability, slip and tenacity. Further, the rheological properties were evaluated. The fluconazole creams with eutectic mixtures had better physical properties. The rheological studies, based on Ostwald de Waele model, showed the pseudoplastic character of flowing at $32^{\circ} \mathrm{C}$ and the correlation between the rheological parameters and the composition of the creams. Moreover, all the preparations had thixotropic properties.
\end{abstract}

Keywords: fluconazole, eutectic mixture, rheology

\section{INTRODUCTION}

Fluconazole, as the synthetic antifungal derivative of the triazole, is used in treatment of the surface mycoses of the skin such as: tinea corporis, tinea cruris, tinea faciei, tinea mannum and tinea pedis [2,15]. The fungicidal activity is the inhibiting of $14 \alpha$ - demethylase that is responsible for the synthesis of ergosterole - the compound required for the synthesis of cell wall [4].

Menthol, a monocyclic monoterpene, is the main component of mint and peppermint of Labiate plants and has a long application history in traditional medicine. Compared with other synthetics, menthol has lower toxic side effects and higher safety [11]. Menthol is also approved as a penetration enhancer in the transdermal transport of several drugs [12].

Salicylic acid is pharmaceutical active substance for topical use. It inhibits the secretion of sebaceous and sweat glands. At low concentration it has keratoplastic and in high doses keratolytic effect. Salicylic acid has a weak antimicrobial activity.



DOI: $10.12923 /$ j.2084-980X/26.4/a.24
Benzocaine is a local anesthetic commonly used as a topical pain reliever. It is the active ingredient in many over-the-counter anesthetic ointments. Benzocaine inhibits the voltage-dependent sodium channels on the nerve membrane, stopping the propagation of the action potential.

Separately, menthol, salicylic acid and benzocaine, are solid bases. When mixed, in certain quantities by weight, however, they form an eutectic mixture (that is the melting point of the mixture is lower than the melting points of the individual components). The eutectic mixture is the oil, thus can be formulated into preparations without the use of a non- aqueous solvent. This allows higher concentrations of ingredients to be formulated into the preparation and maintained during application. The examples of such mixtures are EMLA - eutectic mixture of equal quantities by weight of lidocaine and prilocaine and ICY RUB GEL - the mixture of benzocaine, menthol and thymol $[9,14,16]$.

The influence of eutectic mixture camphor - menthol on physical properties of hydrogels with ibuprofen have been studied by Gohel et al. They have found that the addition of eutectic mixtures cause decreasing of hydrogels viscosity and increasing of ibuprofen release [8]. The same authors describe the formulation and characterization of transdermal fluconazole spray [7]. 
The purpose of our research was to prepare the antifungal creams with fluconazole containing eutectic mixture: menthol-salicylic acid or menthol-benzocaine and to compare and estimate the influence of these mixtures on physical properties of these preparations.

\section{MATERIALS AND METHODS}

Chemicals. Fluconazole, Lanatte wax N PH, Speciol V95G were received as a gift from 3V Sigma SPA, IMCD, Warsaw; Ethanol-P.P.H. "Stanlab" Lublin; Liquid paraffin - Galenic Laboratory Olsztyn; White Petrolatum - Galenic Laboratory PZF Cefarm Lublin; Salicilic acid, Menthol, Benzocaine - POCH Gliwice.

Apparatus. Extensometer; Ultratermostat MLW UH 4 - VEB MLW Medingen Germany; Mixer Cito-UNGUATOR c/s-EPRUS, Rheotest 2 Medingen viscometer (Germany).

Preparations. Four kinds of preparations (cream I, cream II, cream III, cream IV) have been prepared. Their compositions are given in Table 1.

Table 1. The composition of the preparations with fluconazole

\begin{tabular}{|l|c|c|c|c|}
\hline Ingredients $(\mathrm{g})$ & Cream I & Cream II & Cream III & Cream IV \\
\hline Fluconazole & - & 2.0 & 2.0 & 2.0 \\
\hline Ethanol 760g/l & 10.0 & 10.0 & 10.0 & 10.0 \\
\hline White petrolatum & 10.0 & 10.0 & 10.0 & 10.0 \\
\hline Liquid paraffin & 10.0 & 10.0 & 10.0 & 10.0 \\
\hline Lanettae WPH & 10.0 & 10.0 & 10.0 & 10.0 \\
\hline Speziol V95 & 2.0 & 2.0 & 2.0 & 2.0 \\
\hline Salicilic acid & - & - & 1.0 & - \\
\hline Menthol & - & - & 1.0 & 1.0 \\
\hline Benzocaine & - & - & - & 5.0 \\
\hline Water & 58.0 & 56.0 & 54.0 & 50.0 \\
\hline
\end{tabular}

\section{Preparing of the hydrophilic creams}

Cream I. Wax lanatte, liquid paraffin and white petrolatum were melted in the dish on a water bath. Then Speciol V 95G (dissolved in water at $75^{\circ} \mathrm{C}$ ) and ethanol were added with continuous stirring.

Cream II. Wax lanatte, liquid paraffin and white petrolatum were melted in the dish on a water bath. Then Speciol V 95G (dissolved in water at $75^{\circ} \mathrm{C}$ ) and fluconazole (dissolved in ethanol) were added with continuous stirring.

Cream III. Wax lanatte, liquid paraffin and white petrolatum were melted in the dish on a water bath. Then Speciol V 95G (dissolved in water at $75^{\circ} \mathrm{C}$ ), fluconazole (dissolved in ethanol) and eutectic mixture of salicylic acid and menthol were added with continuous stirring.

Cream $I V$. Wax lanatte, liquid paraffine and white petrolatum were melted in the dish on a water bath. Then Speciol V 95G (dissolved in water at $75^{\circ} \mathrm{C}$ ), fluconazole (dissolved in ethanol) and eutectic mixture of benzocaine and menthol were added with continuous stirring.

All preparations were homogenized in Unguator ${ }^{\circledR}$ in order to obtain the uniform consistency.

\section{Evaluation of the physical properties of preparations}

Determination of the spreadability. Determination of the spreadability was conducted in extensometer at $25^{\circ} \mathrm{C}$ \pm 0.1 . The apparatus consists of the larger glass plate fixed in a holder and a second mobile glass plate [1]. The sample of $1 \mathrm{~cm}^{3}$ of cream was applied into the centre of the larger glass plate and the second plate was put on the sample. The weight of $200 \mathrm{~g}$ of each cream was placed on the upper glass plate in every one minute (for 5 minutes). After every minute the diameter of the spread sample was measured. The experiments were performed in triplicate and mean diameter was calculated [6]. The relationships between the load and stretched surface of the preparations $\left(\mathrm{mm}^{2}\right)$ are showed on Fig. 1.

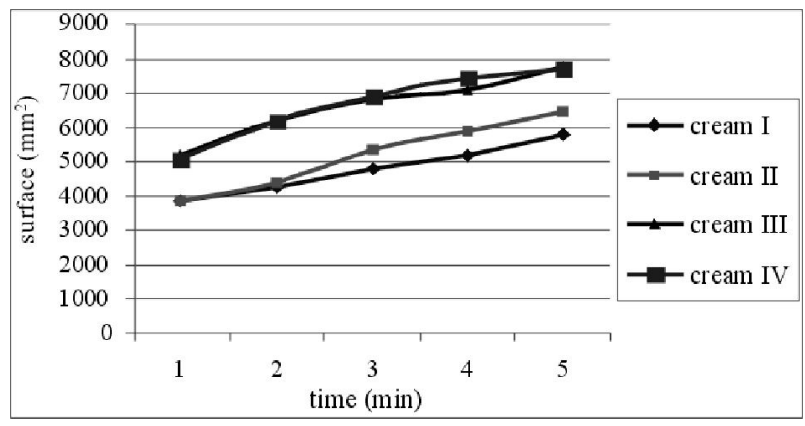

Fig. 1. Spreadability of the creams

Determination of the slip. In slip test the load, causing the move of two plates with the preparation between them, was measured. The results are showed as the average \pm SE (standard error) of five calculations on Fig 2 .

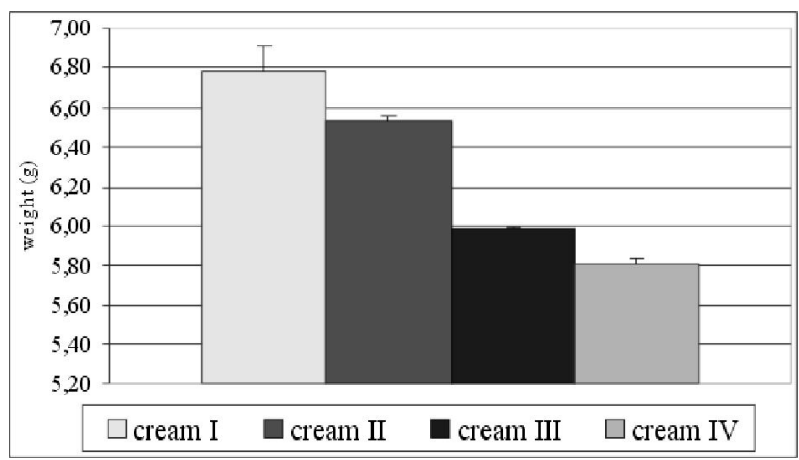

Fig. 2. Studies of the slip

Determination of the tenacity. The tenacity test was conducted in special apparatus according to Münzel project [13]. The apparatus consists of two stainless steel plates of $27 \mathrm{~mm}$ in diameter. The lower plate is attached to the base; the upper is suspended by a string of balance dish. On the lower plate, an equal amount of cream was applied to and covered with a top plate. About $5 \mathrm{~g}$ of weigh was added every $20^{\text {th }}$ second until detachment of the plate. Average results of 6 measurements with the standard error (SE) are presented on the Fig. 3. 


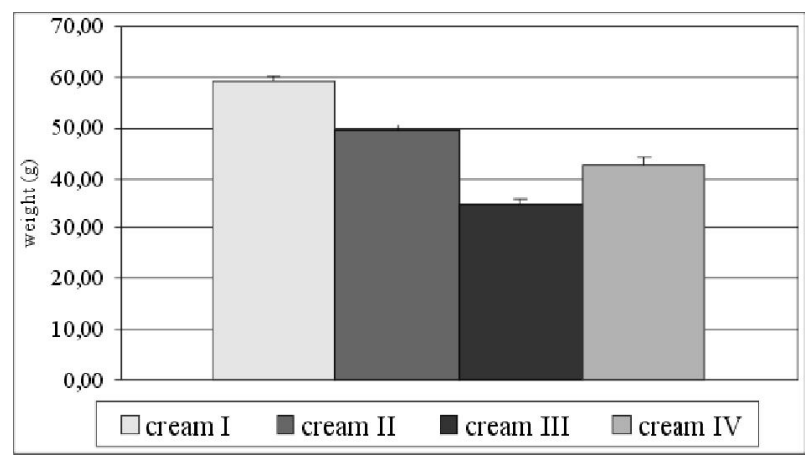

Fig. 3. Studies of the tenacity

Rheological studies. Rheological studies are very important in the evaluation of creams. In this way we can determine the stability, viscosity and character of fluidity of these preparations. It is also important to examine if thixotropy appears $[3,10]$.

In our research "Rheotest-2" Medingen viscometer with coaxial cylinders $\mathrm{S} / \mathrm{S} 1$ was used. The measurements were conducted at $20^{\circ} \mathrm{C}$ and $32^{\circ} \mathrm{C}$. The aim of these studies was calculation the shear stress $\left(\tau_{\mathrm{r}}\right)$ and apparent viscosity $(\eta)$ at the determined values of shear rates $\left(D_{r}\right)$ in the range of $1.5 \mathrm{~s}^{-1}-646 \mathrm{~s}^{-1}$. The samples of the creams were shared in the range of increasing and decreasing shear rates. Each cream was examined three times. After calculation of shear stress $\left(\tau_{r}\right)$ the graphs $\tau_{r}=f\left(D_{r}\right)($ Fig. 4, 5) and the graphs $\eta=f\left(D_{r}\right)$ (Fig. 6, 7) were made.

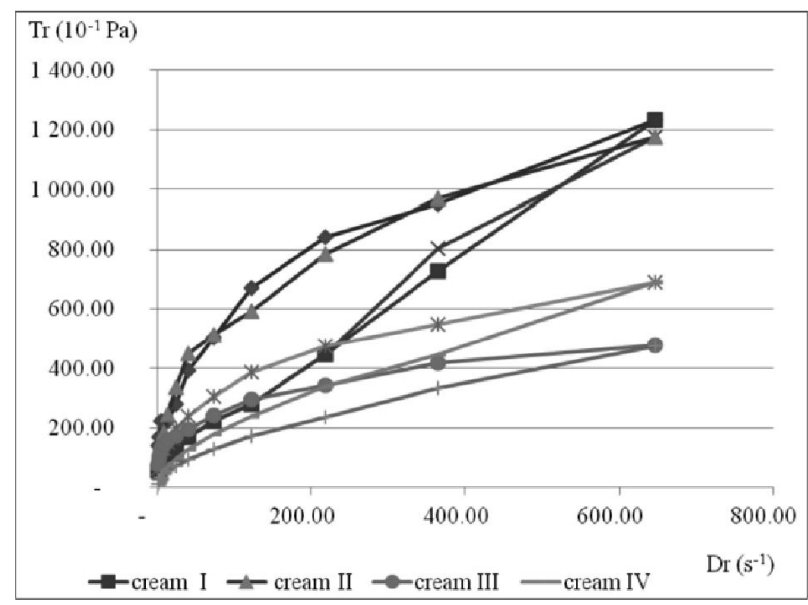

Fig. 4. Ascending and descending rheogram for the creams I,II,III,IV at $20^{\circ} \mathrm{C}$

Then, using Ostwald de Waele power-law model (Eq. 1) [5], the relative viscosity coefficient (k) and power exponent (n) were calculated (Tab. 2).

$$
\tau_{\mathrm{r}}=\mathrm{k} \cdot \operatorname{Dr}^{\mathrm{n}}
$$

where:

$\tau_{\mathrm{r}}-$ shear stress,

$\mathrm{k}$ - relative viscosity coefficient,

$\mathrm{n}$ - power exponent,

$D_{\mathrm{r}}-$ shear rate.

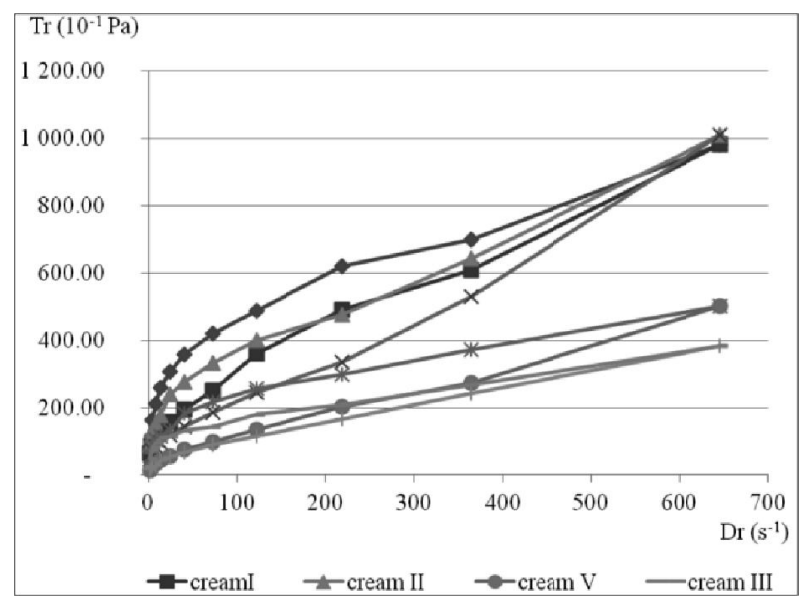

Fig. 5. Ascending and descending rheogram for creams I,II,III,IV at $32^{\circ} \mathrm{C}$

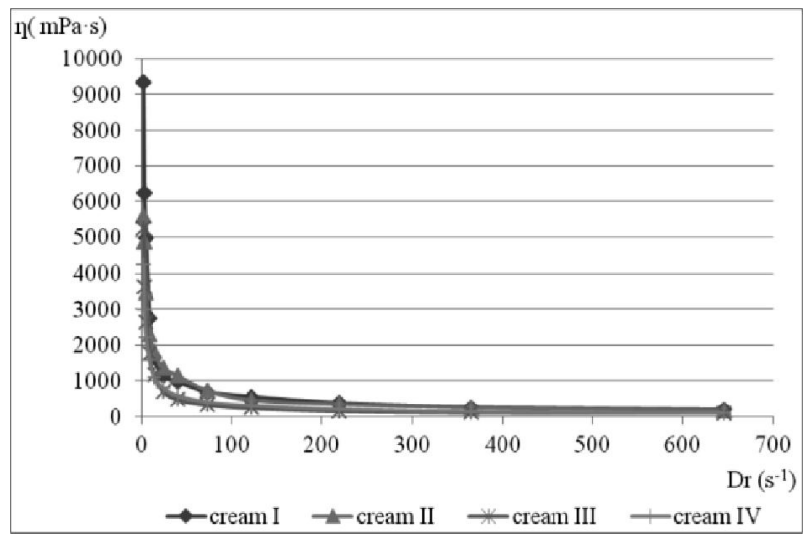

Fig. 6. Creams viscosity curves I,II,III,IV at $20^{\circ} \mathrm{C}$

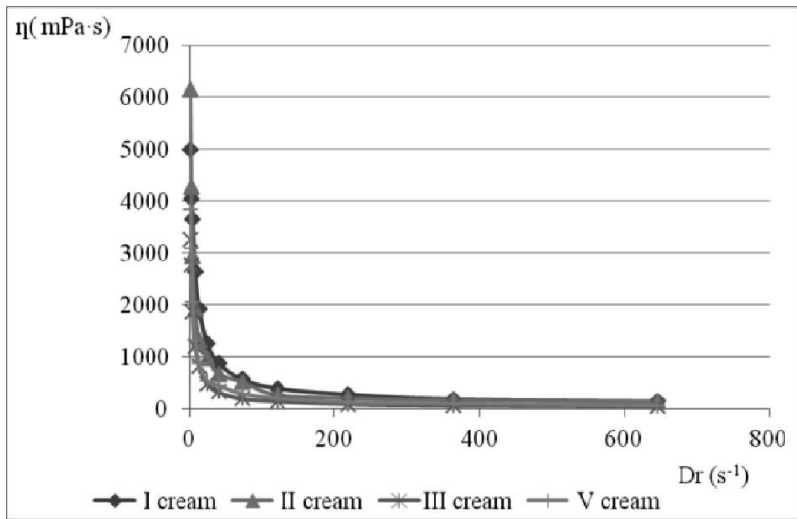

Fig. 7. Creams viscosity curves I,II,III,IV at $32^{\circ} \mathrm{C}$

All creams have thixotropy, which is confirmed by the occurrence of characteristic hysteresis loops. The values of the hysteresis loop areas are presented in Table 2.

Table 2. The calculated values of $\mathrm{n}, \mathrm{k}, \Delta \mathrm{H}$ for creams at 20 and $32^{\circ} \mathrm{C}$

\begin{tabular}{|l|c|r|r|r|r|}
\hline Temp. $\left({ }^{\circ} \mathrm{C}\right)$ & Const & Cream I & Cream II & Cream III & Cream IV \\
\hline \multirow{3}{*}{$20^{\circ} \mathrm{C}$} & $\mathrm{k}$ & 99.53 & 81.04 & 73.15 & 55.09 \\
\cline { 2 - 6 } & $\mathrm{n}$ & 0.21 & 0.42 & 0.29 & 0.40 \\
\cline { 2 - 6 } & $\Delta \mathrm{H}$ & 122529 & 97363 & 50294 & 59815 \\
\hline \multirow{3}{*}{$32^{\circ} \mathrm{C}$} & $\mathrm{k}$ & 82.64 & 74.57 & 50.09 & 53.03 \\
\cline { 2 - 6 } & $\mathrm{n}$ & 0.38 & 0.37 & 0.28 & 0.33 \\
\cline { 2 - 6 } & $\Delta \mathrm{H}$ & 64210 & 68578 & 21079 & 51396 \\
\hline
\end{tabular}

$\mathrm{k}$ - relative viscosity coefficient (mPa.s), $\mathrm{n}$ - power exponent, $\Delta \mathrm{H}$ - hysteresis loop area $(\mathrm{mPa} \cdot \mathrm{s})$ 


\section{RESULTS AND DISCUSSION}

Creams with eutectic mixtures (III and IV) have larger spreadability than the basic cream I and cream II without eutectic mixture, but the kind of eutectic mixture has no effect on the size of spreading (Fig. 1).

The slip and tenacity studies show that the addition of eutectic mixtures enhances the quality of the creams (Fig. $2,3)$. The slip was $6.53 \mathrm{~g}$ for cream II, but $5.99 \mathrm{~g}$ for cream III and $5.81 \mathrm{~g}$ for cream IV. Whereas the tenacity of cream II was $49.67 \mathrm{~g}$, but for creams with eutectic mixtures was respectively $34.57 \mathrm{~g}$ and $42.79 \mathrm{~g}$ for creams III and IV.

Rheological studies at $20^{\circ} \mathrm{C}$ show that cream I and cream II have plastic character of flowing with yield value $\tau_{\mathrm{ro}}=88.00 \mathrm{mPa}$ for cream I and $\tau_{\mathrm{ro}}=78.82 \mathrm{mPa}$ for cream II. The creams with the eutectic mixture behave like pseudoplastic systems without explicitly specified $\tau_{\text {ro. }}$. However, at $32^{\circ} \mathrm{C}$ all creams are pseudoplastic. Both at $20^{\circ} \mathrm{C}$ and $32^{\circ} \mathrm{C}$ all creams have thixotropic properties, but creams I and II have the largest hysteresis loop areas at $20^{\circ} \mathrm{C}(\Delta \mathrm{H}=112592 \mathrm{mPas}$ for cream $\mathrm{I}$ and $\Delta \mathrm{H}=97363$ $\mathrm{mPas}$ for cream II). The addition of the eutectic mixtures in creams III and IV causes decreasing of thixotropy $(\Delta \mathrm{H}$ $=50294 \mathrm{mPas}$ for cream III and $\Delta \mathrm{H}=59815 \mathrm{mPas}$ for cream IV). At $32^{\circ} \mathrm{C}$ all creams have lower thixotropy.

The values of relative viscosity coefficient $(\mathrm{k})$, calculated by using Ostwald de Waele model, at $20^{\circ} \mathrm{C}$ show that cream I has the highest relative viscosity $(\mathrm{k}=99.53$ $\mathrm{mPas}$ ), the addition of eutectic mixtures causes decreasing of relative viscosity coefficient $(\mathrm{k}=73.15 \mathrm{mPas}$ for cream III and $\mathrm{k}=55.09 \mathrm{mPas}$ for cream IV). At $32^{\circ} \mathrm{C}$ the values of relative viscosity coefficient $(\mathrm{k})$ are lower, but creams I and II still have higher $\mathrm{k}$ than creams with eutectic mixtures.

The eutectic mixtures enhance physical properties of creams III and IV, that is why increasing of fluconazole release in comparison with the pure creams I and II can be expected. Thus, the influence of eutectic mixtures on fluconazole release from creams will be the aim of our next studies.

\section{CONCLUSIONS}

1. The using of eutectic mixtures for preparing antifungal creams with fluconazole enhances their physical parameters such as spreadability, slip and tenacity.

2. The mathematical description of rheological parameters of the preparations is based on Ostwald de Waele power-law model.

3. There is a correlation between the rheological parameters and the composition of creams - when the power exponent (n) is relatively constant, relative viscosity coefficient $(\mathrm{k})$ will increase for creams with eutectic mixtures.
4. The increase of temperature does not cause the loss of thixotropic properties.

\section{REFERENCES}

1. Achim M. et al.: Topical dosage forms containing fluidextract of Ruscus aculeatus: Formulation, preparation and physical characterization. Clujul Medical, 83, 99-103, 2010.

2. Ayub A.C. et al.: Topical delivery of fluconazole: In vitro skin penetration and permeation using emulsions as dosage forms. Drug Dev.I. Pharm., 33, 273-280, 2010

3. Bonacucina G., Martelli S., Palmieri G.F.: Rheological, mucoadhesive and release properties of Carbopol gels in hydrophilic cosolvents. Int. J. Pharm., 282, 115-130, 2004.

4. Charlier C. et al.: Fluconazole for the management of invasive candidiasis: where do we after 15 years? J. Antimicrob. Chemother., 57, 384 -410, 2006.

5. Ferguson J., Kembłowski Z.: Reologia stosowana płynów. Wyd. Łódź 1995.

6. Fiebieg A., Janicki St., Sznitowska M.: Farmacja stosowana. PZWL Warszawa 2004.

7. Gohel M.C., Nagori S.A.: Fabrication and design of transdermal fluconazole spray. Pharm. Dev. Technol., 14, 208-215, 2009.

8. Gohel M.C., Nagori S.A.: Fabrication and evaluation of hydrogel thickened microemulsion of ibuprofen delivery. Indian J. Pharm. Educ., 44, 189-194, 2010.

9. Gupta D. et al.: A comparative evaluation of local application of the combination of eutectic mixture of local anesthetics and capsaicin for attenuation of venipuncture pain. Anesth. Analg., 116, 568-571, 2013.

10. Islam M.T. et al: Rheological characterization of topical Carbomer gels neutralized to different pH. Pharm. Res., 7, 1192-1199, 2004.

11. Jingjing L. et al.: The effects of combined menthol and borneol on fluconazole permeation through the cornea ex vivo. Eur. J. Pharmacol., 688, 1-5, 2012.

12. Krishnaiah Y.S.R., Satyanarayana V., Karthikeyan R.S.: Penetration enhancing effect of menthol on the percutaneous flux of nicardipine hydrochloride through excised rat epidermis from hydroxypropyl cellulose gels. Pharm. Dev. Technol., 7, 305-315, 2002.

13. Krówczyński L.: Technologia postaci leków. PZWL Warszawa 1969.

14. Maddi R. et al.: Evaluation of a new cutaneous topical anesthesia preparation. Reg. Anesth., 15, 109-112, 1990.

15. Martin M.V.: The use of fluconazole and itraconazole in the treatment of Candida albicans infections: a review. J. Antimicrob. Chemother., 44, 429-437, 1999.

16. Ohzeki K. et al.: Local anesthetic cream prepared from lidocaine-tetracaine eutectic mixture. Yakugaku Zasshi, $128,611-616,2008$ 